\title{
Cervical Cancer by AJCC v8 Stage
}

National Cancer Institute

\section{Source}

National Cancer Institute. Cervical Cancer by AJCC v8 Stage. NCI Thesaurus. Code C139733.

A term that refers to the staging of cervical cancer according to the American Joint Committee on Cancer, 8th edition. 